\title{
Selective $N$-methylation of primary aliphatic amines with dimethyl carbonate in the presence of alkali cation exchanged Y-faujasites
}

\author{
Maurizio Selva* and Pietro Tundo \\ Dipartimento di Scienze Ambientali dell'Università Ca' Foscari, Calle Larga S. Marta 2137, 30123 Venezia, Italy
}

Received 17 July 2003; revised 18 August 2003; accepted 3 September 2003

\begin{abstract}
The $N$-methylation of aliphatic amines $\left[\mathrm{XC}_{6} \mathrm{H}_{4}\left(\mathrm{CH}_{2}\right)_{n} \mathrm{NH}_{2} ; n=1, \mathrm{X}=\mathrm{H}(\mathbf{1 a}), o-\mathrm{MeO}(\mathbf{1 b}), p-\mathrm{MeO}(\mathbf{1 c}) ; n=2, \mathrm{X}=\mathrm{H}\right.$ (2a), $o-\mathrm{MeO}$ (2b); 1d: $\mathrm{PhCH}(\mathrm{Me}) \mathrm{NH}_{2}$ ] with dimethyl carbonate (DMC) is efficiently catalysed by NaY faujasite: on condition that $\mathrm{CO}_{2}$ (a co-product of the reaction) is carefully removed, $N$-methyl- and $N, N$-dimethyl-amines (RNHMe and $\mathrm{RNMe}_{2}$ ) are obtained in good overall yields (70-90\%). Otherwise, in the presence of $\mathrm{CO}_{2}$, carbamates $\left(\mathrm{RNHCO}_{2} \mathrm{Me}\right)$ form competitively to a large extent. The reaction probably proceeds through a $\mathrm{B}_{\mathrm{Al}} 2$ displacement of the amine on DMC.

(C) 2003 Elsevier Ltd. All rights reserved.
\end{abstract}

In the presence of alkali cation exchanged Y-faujasites (e.g. NaY and KY), the reaction of dimethyl carbonate with primary aromatic amines affords the corresponding mono- $N$-methyl derivatives with unprecedented selectivity $(92-99 \%)$. This holds even for anilines deactivated by both electronic and steric effects (Scheme 1). ${ }^{1}$

Besides the synthetic outcome, this reaction shows relevant environmentally benign features: it uses a nontoxic methylating agent (DMC) coupled with eco-safe solids (zeolites) as catalysts, it does not require additional solvents, and neither organic nor inorganic byproducts are formed. ${ }^{2}$

As a part of our research program on the reactivity of DMC over Y zeolites, we were interested in the $N$ methylation of primary aliphatic amines as well. The higher nucleophilicity of these substrates posed a severe limitation to the reaction selectivity, due not only to the double $N$-methylation but primarily, to the formation of carbamates (Scheme 2). ${ }^{\text {a,c }}$ Apparently, $\mathrm{B}_{\mathrm{Ac}} 2$ and $\mathrm{B}_{\mathrm{Al}} 2$ mechanisms, i.e. the attack of the amine to the carbonyl $\left(\mathrm{B}_{\mathrm{Ac}} 2\right)$ and to the methyl $\left(\mathrm{B}_{\mathrm{Al}} 2\right)$ groups of DMC, were possible without any discrimination.

In this paper, we wish to report a further investigation on this reaction which discloses the synthetic potential for the preparation of $N$-methyl amines and some relevant features of the methylation/methoxycarbonylation mechanisms of aliphatic amines with DMC.

Initially, benzylamine 1a, $o$ - and $p$-methoxybenzylamine, and ( $\alpha$-methyl)benzylamine (compounds $\mathbf{1 b}, \mathbf{1}$, and 1d respectively) were chosen as substrates (Table 1). In a typical procedure (entry 7), a three-necked, jacketed, $25 \mathrm{~mL}$ round-bottomed flask fitted with a $\mathrm{N}_{2}$-bubbler, an adapter for the withdrawal of samples, a reflux condenser connected to a gas flowmeter, and a magnetic bar, was loaded with a solution of benzylamine (1a, $0.3 \mathrm{~g}, 2.8 \mathrm{mmol})$ in dimethyl carbonate $(20$ $\mathrm{mL})$, and $\mathrm{NaY}(0.9 \mathrm{~g})$. The flask was heated at the reflux temperature of $\mathrm{DMC}\left(90^{\circ} \mathrm{C}\right)$, while the mixture was vigorously stirred. A $\mathrm{N}_{2}$ flow of $\sim 25 \mathrm{~mL} / \mathrm{min}$ was

$$
\begin{gathered}
\mathrm{XC}_{6} \mathrm{H}_{4} \mathrm{NH}_{2}+\mathrm{MeOCO}_{2} \mathrm{Me} \underset{130-150{ }^{\circ} \mathrm{C}, 5-8 \text { bar }}{\stackrel{\text { Y-zeolites }}{\longrightarrow}} \mathrm{XC}_{6} \mathrm{H}_{4} \mathrm{NHMe}+\mathrm{MeOH}+\mathrm{CO}_{2} \\
\mathrm{X}=\mathrm{H}, p \text {-Me, } p \text {-MeO, } p \text {-Et, } p \text {-EtO, } p-\mathrm{O}_{2} \mathrm{~N}, p-\mathrm{NC}, o-\mathrm{CH}_{3} \mathrm{OOC}, 2,6-\mathrm{Me}_{2}
\end{gathered}
$$

Scheme 1. Mono- $N$-methylation of anilines with DMC.

\footnotetext{
* Corresponding author. Tel.: +39 041234 8687; fax: +39 041234 8620; e-mail: selva@unive.it 


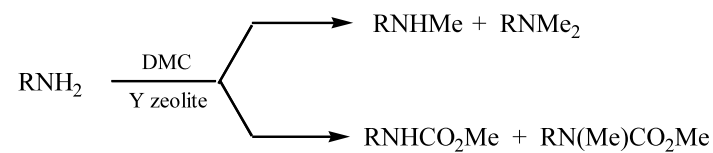

Scheme 2. $\mathrm{R}=\mathrm{CH}_{2} \mathrm{Ph}, \mathrm{Cy}$.

bubbled into the mixture and mantained throughout the reaction. At intervals, samples $(0.1 \mathrm{~mL})$ were withdrawn and were analyzed by both GC and GC/MS. The structures of the products were also confirmed by comparison with authentic samples of $N$-methylbenzylamine, $N, N$-dimethylbenzylamine, methyl $N$-benzyl carbamate, and methyl $N$-benzyl, $N$-methyl carbamate.

The same reaction was also performed under a static $\mathrm{N}_{2}$-atmosphere (entries 1-6).

According to our previous experiments, ${ }^{1 \mathrm{c}}$ without the $\mathrm{N}_{2}$-bubbling, the increase of Lewis acidity of the catalyst (going from $\mathrm{CsY}$ to $\mathrm{LiY}$ faujasites) ${ }^{3}$ shows a positive effect on the reaction rate (compare entries 1-2 and $5)$.

However, at higher conversions (89 and 97\%: entries $3-4)$, the selectivity $\left(S_{\text {Met }}\right)$ towards the $N$-methylation reaction is clearly variable (43 and $64 \%$, respectively). Competitive side reactions, i.e. the carbamation (prod- ucts $\mathbf{C}$ and $\mathbf{M C}$, Scheme 2) and the oxidative deamination (product $\mathbf{E}: \mathrm{XC}_{6} \mathrm{H}_{4} \mathrm{CH}_{2} \mathrm{~N}=\mathrm{CHPh}$ ) of the amine 1a take place to a large extent. ${ }^{4}$ The Brönsted acidic zeolite (HY) is even more unsatisfactory (entry 6): at a $30 \%$ conversion, $S_{\mathrm{Met}}$ is only $33 \%$. We suggest that a strong acid-base interaction may hold amine within the catalyst pores, ${ }^{5}$ so that any advantage due to the smaller size of the cation is cancelled.

Much better results can be gathered for the $N$-methylation of compound 1a as well as of $\mathbf{1 b}-\mathbf{d}$, when reactions are performed over $\mathrm{NaY}$ - a commercially available faujasite - in the presence of a $\mathrm{N}_{2}$ stream (entries 7-10): $S_{\text {Met }}$ of $91-100 \%$ are attained at conversions of $70-94 \%$. This improvement arises not only from the increase of the methylation versus carbamation selectivity $\left(S_{\mathrm{Met} / \mathrm{Carb}}\right)$, but also from a fall in formation of the side-product $\mathbf{E}$.

The same procedure is profitable also for the reaction of phenethylamine (2a) and its $o$-methoxyderivative [2b: $\left.o-\mathrm{MeOC}_{6} \mathrm{H}_{4}\left(\mathrm{CH}_{2}\right)_{2} \mathrm{NH}_{2}\right]$ with DMC. The presence of a $\mathrm{N}_{2}$ flow is an extremely simple and efficient method to allow an excellent $N$-methylation selectivity (91-98\%) for compounds $\mathbf{2 a}-\mathbf{b}$, while the carbamation reaction is practically ruled out.

The data in Table 1 give a clear indication of the major role played by the $\mathrm{CO}_{2}$ which, as is shown in Scheme 1,

Table 1. $N$-Methylation of amines 1a-d and 2a-b with DMC over MY zeolites

\begin{tabular}{|c|c|c|c|c|c|c|c|c|c|c|c|c|c|}
\hline \multirow[b]{2}{*}{ Entry } & \multirow[b]{2}{*}{ Amine } & \multirow[b]{2}{*}{ MY } & \multirow[b]{2}{*}{$T\left({ }^{\circ} \mathrm{C}\right)$} & \multirow[b]{2}{*}{$t(\mathrm{~h})$} & \multirow[b]{2}{*}{$\mathrm{N}_{2}$ flow } & \multirow[b]{2}{*}{ Conv. (\%) } & \multicolumn{5}{|c|}{ Products $(\%)^{\mathrm{a}}$} & \multirow[t]{2}{*}{$S_{\mathrm{Met} / \mathrm{Carb}}^{\mathrm{b}}(\%)$} & \multirow[t]{2}{*}{$S_{\mathrm{Met}}{ }^{\mathrm{c}}(\%)$} \\
\hline & & & & & & & $\mathbf{M}$ & D & C & MC & $\mathbf{E}$ & & \\
\hline 1 & $1 \mathrm{a}$ & LiY & 90 & 7 & No & 43 & 34 & 9 & & & & & \\
\hline 2 & $1 \mathrm{a}$ & $\mathrm{NaY}$ & 90 & 7 & No & 40 & 30 & 7 & & & 3 & & \\
\hline 3 & $1 \mathrm{a}$ & $\mathrm{NaY}$ & 90 & 56 & $\mathrm{No}$ & 89 & 8 & 49 & 7 & 13 & 12 & 74 & 64 \\
\hline $4^{\mathrm{d}}$ & $1 a$ & $\mathrm{NaY}$ & 110 & 23 & No & 97 & - & 42 & 16 & 27 & 12 & 49 & 43 \\
\hline 5 & $1 a$ & $\mathrm{CsY}$ & 90 & 22 & No & 36 & 18 & 8 & & & 10 & & 72 \\
\hline 6 & $1 \mathbf{a}$ & HY & 90 & 23 & No & 30 & 6 & 4 & 8 & & 12 & 55 & 33 \\
\hline 7 & $1 \mathrm{a}$ & $\mathrm{NaY}$ & 90 & 48 & Yes & 94 & 20 & 70 & 3 & & 1 & 98 & 96 \\
\hline 8 & 1b & $\mathrm{NaY}$ & 90 & 23 & Yes & 70 & 30 & 34 & 5 & & 1 & 91 & 91 \\
\hline 9 & $1 c$ & $\mathrm{NaY}$ & 90 & 22 & Yes & 90 & 37 & 51 & 1 & & 1 & 99 & 98 \\
\hline $10^{\mathrm{e}}$ & 1d & $\mathrm{NaY}$ & 90 & 68 & Yes & 70 & 48 & 22 & & & & 100 & 100 \\
\hline 11 & $2 a$ & $\mathrm{NaY}$ & 90 & 24 & Yes & 90 & 39 & 48 & 2 & & & 98 & 98 \\
\hline 12 & $2 b$ & $\mathrm{NaY}$ & 90 & 26 & Yes & 63 & 20 & 37 & 7 & & & 91 & 91 \\
\hline
\end{tabular}<smiles>[X]c1ccccc1NCNCC</smiles>

$M$

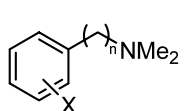

D<smiles>[X]c1ccccc1NC(=O)OC</smiles>

C<smiles>[X]c1ccccc1CN(C)C(=O)OC</smiles>

MC

if $\mathrm{n}=1$ (entries 1-9), $\mathrm{X}=\mathrm{H}, o-\mathrm{MeO}, p-\mathrm{MeO}$; if $\mathrm{n}=2$ (entries 11-12), $\mathrm{X}=\mathrm{H}, o-\mathrm{MeO}$

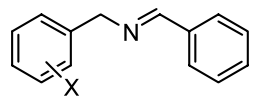

$\mathbf{E}: \mathrm{X}=\mathrm{H}, o-\mathrm{MeO}, p-\mathrm{MeO}$

\footnotetext{
a The structures of all products were assigned by GC/MS analyses and by comparison with authentic samples.

${ }^{\mathrm{b}}$ Methylation versus carbamation selectivity, $S_{\mathrm{Met} / \mathrm{Carb}}=[\mathbf{M}+\mathbf{D} /(\mathbf{M}+\mathbf{D}+\mathbf{C}+\mathbf{M C})] \times 100$.

${ }^{\mathrm{c}}$ Overall $N$-methyl selectivity, $S_{\mathrm{Met}}=[\mathbf{M}+\mathbf{D} /(\mathbf{M}+\mathbf{D}+\mathbf{C}+\mathbf{M C}+\mathbf{E})] \times 100$.

${ }^{\mathrm{d}}$ Entry 4: the reaction was carried out in a stainless-steel autoclave of $150 \mathrm{~mL}$.

${ }^{\mathrm{e}}$ Products $\mathbf{M}, \mathbf{D}, \mathbf{C}$, and $\mathbf{M C}$ of entry 10 were obtained according to the structure of the reacting substrate $\mathbf{1 d}: \mathrm{PhCH}(\mathrm{Me}) \mathrm{NH}_{2}$.
} 
is an intrinsic co-product of DMC-mediated methylation reactions. As far as the methylation proceeds, $\mathrm{CO}_{2}$ chemisorbs into the catalyst cages, ${ }^{6}$ where it becomes available for the reactant amine to form the corresponding urethanes (Eq. (1)). ${ }^{7}$

$$
2 \mathrm{RNH}_{2}+\mathrm{CO}_{2} \rightleftharpoons \mathrm{RNHCO}_{2}^{-} \mathrm{RNH}_{3}^{+} \stackrel{\mathrm{DMC}}{\rightarrow} \mathrm{RNHCO}_{2} \mathrm{Me}
$$

The $\mathrm{B}_{\mathrm{Ac}} 2$ mechanism of Scheme 2 through the attack of the amine to the carbonyl of DMC cannot take place directly. On the other hand, when the zeolite surface is kept free from $\mathrm{CO}_{2}$, the carbamation is hindered and the aliphatic amine reacts only via the $\mathrm{B}_{\mathrm{Al}} 2$ mechanism: $N$-methylation takes place exclusively (Eq. (2)).

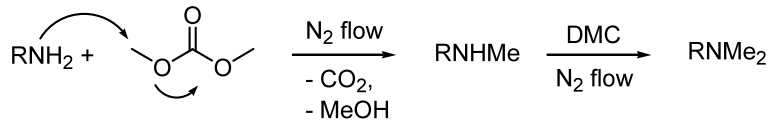

It should be noted that this behavior is peculiar to the explored conditions and particularly to the catalyst used. While the reaction of aliphatic amines and DMC does not proceed significantly without a catalyst, in the presence of $\gamma-\mathrm{Al}_{2} \mathrm{O}_{3}$, carbamates form in good to excellent yields $(80-95 \%) .{ }^{8}$ Furthermore, this reaction occurs without any $\mathrm{CO}_{2}$ promotion: under the conditions of entries 7-12 of Table 1, benzylamine reacts with DMC over $\gamma-\mathrm{Al}_{2} \mathrm{O}_{3},{ }^{9}$ to give methyl $N$-benzylcarbamate as the sole product ( $24 \%$ after $4 \mathrm{~h}$, Scheme 3 ).

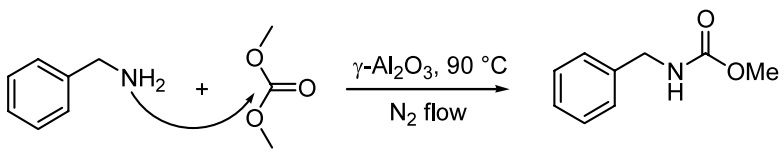

Scheme 3. Direct $B_{A c} 2$ attack of benzylamine on DMC.

The direct $\mathrm{B}_{\mathrm{Ac}} 2$ attack of the amine on the DMC carbonyl is allowed in this case.

With $\mathrm{Y}$ faujasites, the involvement of $\mathrm{CO}_{2}$ in the reaction of aliphatic amines with DMC may also account for the lack of mono- $N$-methyl selectivity in such reactions. In fact, the mechanism proposed for the formation of mono- $N$-methylanilines as well as mono-C-methyl derivatives of $\mathrm{CH}_{2}$-active compounds - though with different catalysts - involves the sequence shown in Scheme 4. ${ }^{1,10}$ The nucleophile $\left(\mathrm{NuH}_{2}\right)$ reacts first with $\mathrm{DMC}$ via the $\mathrm{B}_{\mathrm{Ac}} 2$ mechanism to yield the methoxycarbonylated derivative $\left[\mathrm{Nu}\left(\mathrm{CO}_{2} \mathrm{Me}\right) \mathrm{H}\right.$, Eq. (2)]. Then methylation $\left(\mathrm{B}_{\mathrm{Al}}{ }^{2}\right.$ mechanism) and demethoxycarbonylation reactions (Eqs. 56) lead to the final product $[\mathrm{Nu}(\mathrm{Me}) \mathrm{H}]$. The sequence of $\mathrm{B}_{\mathrm{Ac}} 2-\mathrm{B}_{\mathrm{Al}}{ }^{2}$ processes preserves $\mathrm{NuH}_{2}$ from a double methylation.

By contrast, the more nucleophilic aliphatic amines directly attack the methyl group of DMC as is shown in Eq. (2), and when $\mathrm{CO}_{2}$ is purged from the reaction mixture, a reversible methoxycarbonylation reaction is not possible. Any selectivity towards mono- $N$-methyl products is ruled out.

On the whole, the following conclusions can be drawn:

(i) MY faujasites are efficient catalysts for the $N$ methylation of aliphatic amines, but a high chemoselectivity (methylation versus carbamation) is reached through the tuning of the acid-base properties of the zeolites and most of all, through the removal of $\mathrm{CO}_{2}$ from the reactant mixture;

(ii) The $\mathrm{B}_{\mathrm{Al}} 2$ displacement of the amine on DMC is the likely reaction mechanism. Accordingly, since the mono- $N$ - versus $N, N$-dimethylation selectivity cannot be controlled, the procedure has valuable potential for synthesis of tertiary amines.

\section{Acknowledgements}

MIUR (Italian Ministry of University and Research) and INCA (Interuniversity Consortium Chemistry for the Environment; grant 'Piano Ambiente Terrestre: Chimica per l'Ambiente' Legge 488/92) are gratefully acknowledged for financial support.

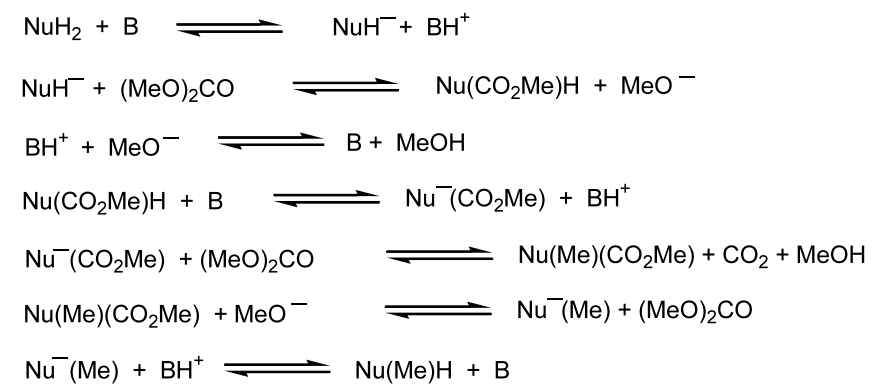

$\mathrm{NuH}_{2}+(\mathrm{MeO})_{2} \mathrm{CO} \longrightarrow \mathrm{Nu}(\mathrm{Me}) \mathrm{H}+\mathrm{CO}_{2}+\mathrm{MeOH}$

Scheme 4. Mono-methylation selectivity with $\mathrm{DMC}$. $\mathrm{NuH}_{2}$ : nucleophile susceptible of double alkylation; $\mathrm{B}$ : a basic site of the catalyst. 


\section{References}

1. (a) Selva, M.; Bomben, A.; Tundo, P. J. Chem. Soc., Perkin Trans. 1 1997, 1041-1045; (b) Selva, M.; Tundo, P.; Perosa, A. J. Org. Chem. 2001, 66, 677-680; (c) Selva, M.; Tundo, P.; Perosa, A. J. Org. Chem. 2002, 67, 9238-9247.

2. Selva, M.; Tundo, P. Acc. Chem. Res. 2002, 35, 706-716.

3. The LiY and CsY zeolites were prepared from $\mathrm{NaY}$ through known procedures (Onaka, M.; Ishikawa, K.; Izumi, Y Chem. Lett. 1982, 1783-1786). The Lewis acidity of these solids is higher with cations having a higher charge to mass ratio: particularly, $\mathrm{Li}^{+}$and $\mathrm{Na}^{+}$mitigate the amine nucleophilicity and due to their smaller size, they allow an easier diffusion of reactants through the zeolite cages. (a) Eberly, P. E. In Zeolite Chemistry and Catalysis; 171, ACS Monograph, Rabo J. A., 1976; (b) Barthomeuf, D. J. Phys. Chem. 1984, 88, 42-45; (c) Rao, J. V. Chem. Commun. 1998, 269; (d) Su, B.; Barthomeuf, D. Stud. Surf. Sci. Catal. 1995, 94, 598-605.

4. In all probability, the formation of product $\mathbf{E}$ is promoted by $\mathrm{O}_{2}$ traces in the reaction mixture. (a)
Toshikazu, H.; Masayoshy, H.; Isao, I.; Yoshiki, O. J. Chem. Soc., Chem. Comm. 1993, 194-195; (b) Kim, J. M.; Cho, I. S.; Mariano, P. S. J. Org. Chem. 1991, 56, 4943-4955.

5. (a) Narayan, S.; Deshpande, K. J. Mol. Catal. 1995, 104, L109-L113; (b) Fesenko, E. A.; Barnes, P. A.; Parkes, G. M. B.; Brown, D. R.; Naderi, M. J. Phys. Chem. B. 2001, 105, 6178-6185.

6. Zecchina, A.; Lamberti, C.; Bordiga, S. Catal. Today 1998, 41, 169-177.

7. (a) Aresta, M.; Quaranta, E. Tetrahedron 1991, 47, 94899502; (b) Aresta, M.; Dibenedetto, A.; Quaranta, E.; Boscolo, M.; Larrson, R. J. Mol. Catal. 2001, 174, 7-13; (c) Selva, M.; Tundo, P.; Perosa, A. Tetrahedron Lett. 2002, 43, 1217-1219.

8. Vauthey, I.; Valot, F.; Gozzi, C.; Fache, F.; Lemaire, M. Tetrahedron Lett. 2000, 41, 6347-6350.

9. We used the same $\gamma-\mathrm{Al}_{2} \mathrm{O}_{3}$ (oxid C) reported in Ref. 8: this catalyst was a generous gift from Degussa.

10. Selva, M.; Marques, C. A.; Tundo, P. J. Chem. Soc., Perkin Trans. 1 1994, 1323-1328. 